\title{
Opuntia ficus-indica L. Mill Residues-Properties and Application Possibilities in Food Supplements
}

\author{
Salvador Manzur-Valdespino $\left.{ }^{1} \mathbb{(}\right)$, Esther Ramírez-Moreno ${ }^{1}{ }^{\circledR}$, José Arias-Rico ${ }^{2}$, \\ Osmar Antonio Jaramillo-Morales $\left.{ }^{3}{ }^{(}\right)$, Zuli Guadalupe Calderón-Ramos ${ }^{1}$, \\ Luis Delgado-Olivares ${ }^{1}{ }^{\mathbb{D}}$, Manuel Córdoba-Díaz ${ }^{4} \mathbb{D}$, Damián Córdoba-Díaz ${ }^{4}$ and \\ Nelly del Socorro Cruz-Cansino ${ }^{1, *(1)}$
}

1 Centro de Investigación Interdisciplinario, Área Académica de Nutrición, Instituto de Ciencias de la Salud, Universidad Autónoma del Estado de Hidalgo, Circuito Ex Hacienda La Concepción S/N, Carretera Pachuca-Actopan, San Agustín Tlaxiaca, Hidalgo 42160, Mexico; salvador_manzur@uaeh.edu.mx (S.M.-V.); esther_ramirez@uaeh.edu.mx (E.R.-M.); zramos@uaeh.edu.mx (Z.G.C.-R.); ldelgado@uaeh.edu.mx (L.D.-O.)

2 Área Académica de Enfermería, Instituto de Ciencias de la Salud, Universidad Autónoma del Estado de Hidalgo, Circuito Ex Hacienda La Concepción S/N, Carretera Pachuca-Actopan, San Agustín Tlaxiaca, Hidalgo 42160, Mexico; jose_arias@uaeh.edu.mx

3 Área Académica de Farmacia, Instituto de Ciencias de la Salud, Universidad Autónoma del Estado de Hidalgo, Circuito Ex Hacienda La Concepción S/N, Carretera Pachuca-Actopan, San Agustín Tlaxiaca, Hidalgo 42160, Mexico; osmar_jaramillo@uaeh.edu.mx

4 Departamento de Farmacia Galénica y Tecnología Alimentaria, Facultad de Farmacia, Universidad Complutense de Madrid, Plaza de Ramón y Cajal s/n, 8040 Madrid, Spain; mcordoba@ucm.es (M.C.-D.); damianco@farm.ucm.es (D.C.-D.)

* Correspondence: ncruz@uaeh.edu.mx; Tel.: +52-771-717-2000 (ext. 4321)

Received: 3 April 2020; Accepted: 4 May 2020; Published: 7 May 2020

Featured Application: In this paper we developed tablets made from Opuntia ficus-indica residues, which can be used as a product of interest for the food supplement industry.

\begin{abstract}
Recently, industry has been focusing on the development of new products made from food by-products in order to reduce and take advantage of food wastes. The objective of this study was to evaluate tablet formulations developed by mixing two commercial excipients, microcrystalline cellulose $(\mathrm{M})$ and $\alpha$-lactose-monohydrate $(\mathrm{L})$, added with powder from residues (mesocarp and pericarp) of green and red ( $G$ and $R$ ) cactus pear fruit (Opuntia ficus-indica L. Mill), having the following formulations: green with microcrystalline cellulose (GM), green with lactose (GL), red with microcrystalline cellulose (RM), and red with lactose (RL). The results showed lower disintegration times for the tablets with microcrystalline cellulose. The fiber functional properties presented good values for lipid and water holding capacity. There was a higher total phenolic content (TPC) in formulations with green cactus pear residue powder with microcrystalline cellulose and lactose (GM and GL, respectively), but the DPPH and ferric reducing/antioxidant power (FRAP) values were higher in the formulations with red cactus pear residues (RM and RL), while ABTS values were similar among all formulations. In conclusion, tablets made from Opuntia residues are proposed as a product of interest for the food supplement industry because of the good quality parameters and the functional and antioxidant properties that they provide.
\end{abstract}

Keywords: Opuntia ficus-indica; residues; tablet; functional properties; antioxidants 


\section{Introduction}

Dietary supplements are important sources of nutrients widely used by the population, and they play an essential role in disease prevention [1]. There are many kinds of dietary supplements, such as vitamins, minerals, herbs, and oils, among others. A dietary supplement is defined "as a product that contains one or more concentrated nutrients [2], with the objective of increasing the intake of some nutrients in the daily diet". These supplements are regulated by the Food and Drug Administration (FDA) as food and not as drugs [3]. Nowadays, the supplement industry is growing fast since people expect to find ready-to-eat products from natural sources such as fruits, vegetables, or herbs with bioactive compounds which promote health [4]. However, several studies have reported that different agro-food by-products such as fruit and vegetable residues, including Opuntia ficus-indica L. Mill residues, possess bioactive compounds with a wide spectrum of pharmacological properties, such as neuroprotective, antidiabetic, antioxidant, anti-inflammatory, hepatoprotective, and anticancer activities, and can be used as raw materials for the development of nutraceuticals, medicines, food, and cosmetics useful to the prevention or control of diseases $[5,6]$.

In this context, the cactus pear fruit (Opuntia ficus-indica L. Mill.) is a product that has been recognized for the health benefits that it can provide, and it has also drawn scientific interest for several years. These species are grown in Mexico and are arborescent plants with elliptic cladodes. Approximately $>90 \%$ of the production of the fruit is of the yellow or green cultivars; the red type is less abundant (7-8\%) [7]. Cactus pear fruit is generally consumed fresh, but it has also the potential to be processed into products like juices or jam [8]. The fruit has juicy pulp with numerous seeds immersed in it, surrounded by a thick peel with small spines [9]. Consumption and processing generate residues such as peels and seeds, which are nonedible portions of the fruit and represent $37 \%$ to $67 \%$ of the total weight [10]. These residues constitute a problem for environmental pollution due to the high amount of wastes produced and the associated fermentation phenomena [11].

The nonedible portion constituting the peel comprises two fractions, the mesocarp and pericarp, which are rich in antioxidants, soluble sugars, and dietary fiber, as well as trace elements such as calcium, magnesium, potassium, and manganese [12,13]. It has been reported that cactus pear peel has twice the dietetic fiber content of the fruit pulp, with a high proportion of insoluble fiber which provides beneficial effects for human health, such as lipid-lowering and hypoglycemic actions [14,15]. In addition, dietary fiber can be linked to antioxidant compounds like polyphenols, flavonoids, or phenolic acids, becoming bioactive in the human intestine once it is released from the food matrix [16]. Different products have been developed with cactus pear residues, such as yogurts, snacks, and margarine [17-19], and some other fruit wastes (pineapple, banana, or orange peels) have been used for the creation of dietary supplements or products for the pharmaceutical industry [20-22].

The drugs or food supplements are introduced into the body through the mouth and are absorbed in the digestive tract; among other dosage forms such as liquids, emulsions, or powders, tablets provide a convenient and easy method of administration [23]. The tablet formulations must observe specific quality parameters that allow the characteristics of the product to be preserved without physical changes during transportation and packaging, as well as evaluation of the dissolution behavior in the human body [24]. It has been widely reported that polymers isolated from fruit or vegetables residues can be used as excipients; however, there has been little research in which the residues are combined with an excipient in the same formulation. In this context, the aim of the present study was to evaluate the quality parameters (uniformity, breaking force, friability, disintegration) and the functional (lipid and water holding capacity) and antioxidant properties (total phenolic content, antioxidant activity by ABTS, DPPH, and ferric reducing/antioxidant power (FRAP)) of tablet formulations developed from cactus pear residues. 


\section{Materials and Methods}

\subsection{Sample Preparation}

Two varieties of cactus pear fruits were selected, green and red Opuntia ficus-indica L. Mill, which were provided by the Mexican Association CoMeNTuna (Consejo Mexicano del Nopal y la Tuna) in Hidalgo, Mexico. The cactus pear fruits were manually harvested (latitude of $20^{\circ} 16^{\prime} 12^{\prime \prime} \mathrm{N}$, longitude $98^{\circ} 56^{\prime} 42^{\prime \prime} \mathrm{W}$, and altitude of $2600 \mathrm{~m}$ above sea level) during September 2015 and were selected in agreement with the Mexican legislation for nonindustrialized food products relating to the human use of cactus pear (Opuntia spp.) fruit, being of firm consistency, clean, free of foreign matter, and free of damage caused by pests or diseases in addition to presenting a state of commercial maturity, determined by the observation of the sinking of the fruit receptacle [25]. The fruits were divided into three batches, washed, and manually peeled; the residues (mesocarp and pericarp) were separated, then frozen to $-32{ }^{\circ} \mathrm{C}$ and lyophilized (VWR26671-581 Labconco, Kansas City, MO, USA) for $96 \mathrm{~h}$ at $-55 \pm 1{ }^{\circ} \mathrm{C}$ under a vacuum of 0.040 mbar. Samples were milled (Blender, 38BL52, LBC10, Waring Commercial, Torrington, CT, USA) and sieved to a particle size of $<500 \mu \mathrm{m}$.

\section{Tablet Formulation}

Formulations were produced as follows: Two commercial excipients, microcrystalline cellulose (Avicel ${ }^{\circledR}$ PH200 FMC Corp., Spain) and $\alpha$-lactose-monohydrate (Tabletose ${ }^{\circledR} 80$ Meggle Milchindustrie GMBH and Co. KG, Wasserburg, Germany), were used at $58 \%$, mixed with $40 \%$ of cactus pear powder, and four formulations were thus developed: green cactus pear residue with microcrystalline cellulose (GM), green cactus pear residue with lactose (GL), red cactus pear residue with microcrystalline cellulose (RM), and red cactus pear residue with lactose (RL). Additionally, $1 \%$ of talcum powder and $1 \%$ of magnesium stearate (Panreac-Montplet and Esteban, Barcelona, Spain) were added as lubricant agents to improve the tablet quality. All components were mixed in a homogenizer (V-mill type MV-6; Turu Grau S.A, Tarrasa, Spain) for 15 min and compacted using an eccentric tableting machine (Bonnals B-40, Barcelona, Spain). These formulations were established according to preliminary tests where the excipients were added until complete compaction was reached.

\subsection{Quality Parameters}

\subsubsection{Mass Uniformity, Thickness, and Diameter}

The uniformity analysis was carried out by randomly selecting 10 units of each formulation and measuring their weight $(\mathrm{g})$, thickness $(\mathrm{mm})$, and diameter $(\mathrm{mm})$ using a tablet tester (WHT-1 Pharma Test, Hainburg, Germany) [26].

\subsubsection{Tablet Breaking Force}

The tablet breaking force is defined as the amount of force required to break a tablet under a diametrical compression test. This was determined using a durometer (PT-B 311 Pharma Test, Hainburg, Germany), applying pressure until the tablets broke. The results are expressed in Newtons (N) [27].

\subsubsection{Friability}

Friability is the tendency of a tablet to lose particles due to abrasion, friction, or mechanical shock. This was determined according to the American Pharmacopoeia Commission (USP 1217) standard using a friability tester (ERWEKA, TA-UZ 127, Heusenstamm, Germany). Ten undusted and weighed tablets were subjected to 100 drum rotations; then, the tablets were removed from the drum, the dust 
was brushed off, and the tablets were weighed again [28]. Friability is expressed as the percentage of mass lost, calculated using Equation (1):

$$
\% \text { Friability }=((\text { starting weight }- \text { weight after test }) / \text { starting weight }) \times 100 \text {. }
$$

\subsubsection{Disintegration}

This test is used to analyze the disintegration of tablets or capsules within the prescribed time when placed in a liquid medium. Six tablets were tested using a disintegrator (ERWEKA, DT-60, Heusenstamm, Germany) with a medium of $0.1 \mathrm{~N}$ hydrochloric acid at $37 \pm 1^{\circ} \mathrm{C}$ at $50 \mathrm{rpm}$. The test was finished when no residue was observed in the bottom of the disintegrator glass, and the disintegration time (min) was measured [29].

\subsection{Scanning Electron Microscopy (SEM)}

Micrographs were taken to establish structural comparisons between formulations. The morphology of the cactus pear formulations was evaluated by SEM. Samples were deposited on a silicon wafer and set into a sputter coater (Denton Vacuum Desk V, USA) for a thin-layer gold coating, applying 20 mTorr and $20 \mathrm{~mA}$ for a duration of $4 \mathrm{~min}$. Samples were observed under a scanning electron microscope (JEOL JSM-6300, USA) at 250 $\times$ magnification.

\subsection{Functional Properties: Lipid and Water Holding Capacity}

The lipid holding capacity (LHC) and water holding capacity (WHC) were measured by mixing $250 \mathrm{mg}$ of the tablet powder with $10 \mathrm{~mL}$ of soybean oil or water in a centrifuge tube, shaking the mixture for a duration of $10 \mathrm{~min}$, and leaving it at room temperature for $24 \mathrm{~h}$ prior to centrifugation (Hamilton Bell, VanGuard V6500 USA) at $3200 \mathrm{rpm}$ for $10 \mathrm{~min}$. The supernatants were decanted and the pellets were weighted. The amount of lipids or water absorbed by the powder is reported as grams of lipids or water retained per gram of sample on a dry basis $(\mathrm{g} / \mathrm{g} \mathrm{db})[30]$.

\subsection{Color Measurement}

Color was measured by placing milled tablets on a circular white plate and using a colorimeter (Minolta CM-80 500 SM-508D, Japan), using the $\mathrm{D}_{65}$ illuminant with an angle of observation of $10^{\circ}$. Color was recorded using the CIE- $L^{*} a^{*} b^{*}$ values, where $L^{*}$ indicates lightness ( $L^{*}$ values of 0 and 100 indicate black and white, respectively), $a^{*}$ is the axis of chromaticity between green $(-)$ and red $(+)$, and $b^{*}$ is the axis between blue (-) and yellow (+). Numerical values of $L^{*}, a^{*}$, and $b^{*}$ were used to obtain the Hue angle $\left(h^{\circ}\right)\left(h^{\circ}=\operatorname{tg}^{-1}(\mathrm{~b} / \mathrm{a})\right)$ and chroma $\left(C=\left[a^{* 2}+b^{* 2}\right]^{1 / 2}\right)$ parameters [31].

\subsection{Antioxidant Properties}

\subsubsection{Extraction of Antioxidants}

To determine the antioxidant properties (total phenolic content (TPC), ABTS, DPPH, and FRAP) aqueous extraction was carried out following the methodology described by Serrano and Saura-Calixto [16]. Briefly, $250 \mathrm{mg}$ of tablets was triturated and placed in tubes, $10 \mathrm{~mL}$ of methanol/water (50:50, v/v) was added, and then the tubes were shaken (LabTech LSI-3016A, Korea) at $60 \mathrm{rpm}$ for $1 \mathrm{~h}$ at room temperature. After this, the tubes were centrifuged at $3200 \mathrm{rpm}$ for $20 \mathrm{~min}$ (Hamilton Bell VanGuard 6500, Montvale, NJ, USA) and the supernatant was recovered to perform a second wash in the pellet, adding $10 \mathrm{~mL}$ of acetone/water $(70: 30, \mathrm{v} / \mathrm{v})$. The shaking and centrifugation processes were repeated, and both the methanolic and acetonic supernatants were combined and graduated to $25 \mathrm{~mL}$ using a 1:1 methanol/water and acetone/water solution. 


\subsubsection{Total Phenolic Content (TPC)}

The total phenolic content was determined following the Folin-Ciocalteu method according to Stintzing et al. [32]. An aliquot $(100 \mu \mathrm{L})$ was mixed with $500 \mu \mathrm{L}$ of diluted Folin-Ciocalteu reagent (1:10). Then, $400 \mu \mathrm{L}$ (7.5\%) of sodium carbonate was added, and the mixture was incubated for $30 \mathrm{~min}$ at room temperature. The absorbance of the mixture was measured at $765 \mathrm{~nm}$ (Power Wave XS UV-Biotek, USA). For the standard curve, gallic acid was used as the reference standard, with concentrations of 0 , 100,200 , and $300 \mathrm{mg}$ of gallic acid/L. The results are expressed as milligrams of gallic acid equivalent per 100 grams on a dry basis (mg GAE/100 g db).

\subsubsection{Antioxidant Capacity by ABTS•+}

The ABTS analysis was performed according to Kuskoski et al. [33], with some modifications. The radical cation 2,2 azino-bis (3-ethylbenzothiazoline-6-sulfonic acid) diammonium salt (ABTS•+) was produced by reacting $7 \mathrm{mM}$ ABTS stock solution with $2.45 \mathrm{mM}$ potassium persulfate under dark conditions at room temperature for a duration of $16 \mathrm{~h}$ before use. The ABTS $\bullet+$ solution was diluted with deionized water until it reached an absorbance of $0.7 \pm 0.1$ at $754 \mathrm{~nm}$. An aliquot of $100 \mu \mathrm{L}$ of sample was added to $900 \mu \mathrm{L}$ of ABTS solution, and the absorbance at $754 \mathrm{~nm}$ (Power Wave XS UV-Biotek, USA) was measured after $7 \mathrm{~min}$ of incubation at room temperature. The standard curve was linear with concentrations of $0,60,120,180,240$, and $300 \mu \mathrm{mol}$ of Trolox/L, and the antioxidant capacity is expressed as micromoles of Trolox equivalents per 100 grams on a dry weight basis $(\mu \mathrm{mol}$ $\mathrm{TE} / 100 \mathrm{~g} \mathrm{db})$.

\subsubsection{Antioxidant Activity by DPPH•}

Antiradical activity was analyzed using the 1,1-diphenyl-2-picrylhydrazyl (DPPH•) radical as described by Aguirre et al. [34]. An ethanolic solution $(7.4 \mathrm{mg} / 100 \mathrm{~mL})$ of the stable DPPH radical was prepared. Then, $100 \mu \mathrm{L}$ of extract was taken into vials and $500 \mu \mathrm{L}$ of DPPH solution was added; the mixture was left to stand for $1 \mathrm{~h}$ at room temperature. Finally, the absorbance was measured at $520 \mathrm{~nm}$ using a microplate reader (Power Wave XS UV-Biotek, USA). A standard curve was constructed with concentrations of $0,50,100,200$, and $300 \mu \mathrm{mol}$ of Trolox/L. The inhibition percentage of the DPPH cation was calculated using Equation (2):

$$
\% \text { Inhibition DPPH }=((\mathrm{Ac}-\mathrm{As}) / \mathrm{Ac}) \times 100
$$

where Ac is the absorbance of the control and As is the absorbance of the sample.

\subsubsection{Ferric Reducing/Antioxidant Power (FRAP)}

The FRAP assay was performed according to the method described by Zafra et al. [35]. The stock solutions included $300 \mathrm{mM}$ acetate buffer (sodium acetate trihydrate $\mathrm{C}_{2} \mathrm{H}_{3} \mathrm{NaO}_{2} \cdot 3 \mathrm{H}_{2} \mathrm{O}$ and glacial acetic acid $\mathrm{C}_{2} \mathrm{H}_{4} \mathrm{O}_{2}$ ), pH 3.6, $10 \mathrm{mM}$; TPTZ (2,4,6-tripyridyl-s-triazine) solution in $40 \mathrm{mM} \mathrm{HCl}$; and $20 \mathrm{mM}$ $\mathrm{FeCl}_{3} .6 \mathrm{H}_{2} \mathrm{O}$ solution. The fresh solution prepared by mixing $25 \mathrm{~mL}$ acetate buffer, $2.5 \mathrm{~mL}$ TPTZ solution, and $2.5 \mathrm{~mL} \mathrm{FeCl} \cdot 6 \mathrm{H}_{2} \mathrm{O}$ solution was warmed at $37^{\circ} \mathrm{C}$ before use. The sample $(30 \mu \mathrm{L})$ was mixed with $90 \mu \mathrm{L}$ of distilled water and $900 \mu \mathrm{L}$ of the FRAP solution for $10 \mathrm{~min}$ in the dark. A quantity of $5 \mathrm{M}$ ferrous sulfate $\left(\mathrm{FeSO}_{4}\right)$ was used as the standard for the calibration curve (concentrations of 0 , 200, 400, 600, 800, and $1000 \mu \mathrm{mol}$ of $\mathrm{FeSO}_{4}$ ). Absorbance was measured at $593 \mathrm{~nm}$ (Power Wave XS UV-Biotek, USA), and the results are expressed as micromoles of Fe(II) per 100 grams on a dry basis $(\mu \mathrm{mol} \mathrm{Fe}(\mathrm{II}) / 100 \mathrm{~g} \mathrm{db})$.

\subsection{Statistical Analysis}

All determinations were performed in triplicate, and the results presented correspond to the average of the triplicate \pm standard deviation. Statistical analyses were conducted using SPSS 23 
(SPSS ${ }^{\circledR}$ for Windows ${ }^{\mathrm{TM}}$ Chicago Illinois), and comparisons between samples were carried out by applying a multivariate analysis of variance (ANOVA). Differences between means were ranked by Tukey's comparison test at a significance level of $p<0.05$.

\section{Results and Discussion}

\subsection{Quality Parameters}

The tablet form represents two-thirds of the worldwide pharmaceutical products commercialized and is one of the most-consumed administration types of natural extracts and drugs [36]. In the pharmaceutical manufacturing process, quality evaluations (of uniformity, hardness, friability, and disintegration, among others) are performed to avoid variation from the pharmacopoeia limits [37]. The quality parameters of the cactus pear residue tablets are shown in Table 1.

Table 1. Quality and functional parameters of cactus pear residue tablet formulations.

\begin{tabular}{ccccc}
\hline & GM & GL & RM & RL \\
\hline Weight $(\mathrm{g})$ & $0.7 \pm 0^{\mathrm{d}}$ & $0.9 \pm 0^{\mathrm{b}}$ & $0.8 \pm 0^{\mathrm{c}}$ & $1 \pm 0^{\mathrm{a}}$ \\
Thickness (mm) & $4.6 \pm 0^{\mathrm{c}}$ & $4.8 \pm 0^{\mathrm{b}}$ & $4.6 \pm 0^{\mathrm{c}}$ & $5.6 \pm 0^{\mathrm{a}}$ \\
Diameter (mm) & $14 \pm 0^{\mathrm{a}}$ & $14 \pm 0^{\mathrm{a}}$ & $14 \pm 0^{\mathrm{a}}$ & $14 \pm 0^{\mathrm{a}}$ \\
Breaking force (N) & $121 \pm 8^{\mathrm{b}}$ & $162 \pm 29^{\mathrm{a}}$ & $164 \pm 29^{\mathrm{a}}$ & $96 \pm 13^{\mathrm{b}}$ \\
Friability (\%) & $0.3 \pm 0^{\mathrm{a}}$ & $0.1 \pm 0^{\mathrm{b}}$ & $0.3 \pm 0^{\mathrm{a}}$ & $0.1 \pm 0^{\mathrm{b}}$ \\
Disintegration (min) & $2 \pm 0^{\mathrm{c}}$ & $66 \pm 2^{\mathrm{a}}$ & $19 \pm 1^{\mathrm{b}}$ & $67.3 \pm 4^{\mathrm{a}}$ \\
LHC (g/g) & $5.3 \pm 0^{\mathrm{a}}$ & $4.5 \pm 0^{\mathrm{b}}$ & $4.5 \pm 0^{\mathrm{b}}$ & $3.8 \pm 0^{\mathrm{c}}$ \\
WHC (g/g) & $5.5 \pm 0^{\mathrm{a}}$ & $4.2 \pm 0^{\mathrm{b}}$ & $4.6 \pm 0^{\mathrm{b}}$ & $3.6 \pm 0^{\mathrm{c}}$
\end{tabular}

Mean values \pm standard deviation $(n=3) .{ }^{\text {a-d }}$ Superscript letters indicate significant differences $(p<0.05)$ between tablet formulations. GM: green cactus pear residue with microcrystalline cellulose; GL: green cactus pear residue with lactose; RM: red cactus pear residue with microcrystalline cellulose; RL: red cactus pear residue with lactose. LHC: lipid holding capacity; WHC: water holding capacity.

The variations in these quality parameters depend directly on the pressing force and the punches selected in the tablet compression machine [38]. The average weight of the tablets ranged from 0.7 to $1 \mathrm{~g}$, RL tablets were significantly heavier, and weight variations from the average were of $0.01 \%$ to $0.05 \%$; all tablets were within the tolerance limits for mass variation $(<5 \%)$ established by the United States Pharmacopoeia Commission [26]. The weight of the cactus pear residue tablets was higher than those reported for tablets made in other studies, such as those containing orange peel pectin and banana peel (0.4 and $0.2 \mathrm{~g}$, respectively) [21,39]. The thickness values were between 4.6 and $5.6 \mathrm{~mm}$, and the RL tablets were significantly thicker $(p<0.05)$ than the other formulations.

Tablet diameter did not differ among the formulations $(14 \mathrm{~mm})$ and could be considered a good size. According to the FDA, a size of $>22 \mathrm{~mm}$ could propitiate a prolonged esophageal transit time, difficulty swallowing, or even injury to the esophagus [40]. In addition, it has been reported that the ideal size for tablets is between 7 and $8 \mathrm{~mm}$ [41].

Evaluation of the hardness parameter is relevant because it is directly related to the resistance against mechanical impacts due to handling, manufacturing, packaging, and transport, and it is also related with tablet disintegration [42]. The breaking force of the cactus pear residue tablets ranged from 96 to $164 \mathrm{~N}$, with the values for GL and RM being higher. The cactus pear residue tablets presented values higher than those reported in tablets made with orange peel pectin (17 to $29 \mathrm{~N}$ ) [22] and banana peel (19 to $22 \mathrm{~N})$ [21].

The percentage of friability indicates the amount of loose particles on the tablet due to mechanical shock. In all formulations, the loss of mass was below 1\%, and according to Porter et al., tablets with friability values of $<1 \%$ are good, while high friability values lead to unacceptable loss of drug content during processing, storage, and handling [43]. The tablets with microcrystalline cellulose (GM and RM) had higher friability (both $0.3 \%$ ) in comparison with the lactose tablets $(0.1 \%$ for GL and RL). These differences could be attributed to the greater resistance to impacts and cohesion force 
of $\alpha$-lactose agglomerates, while cellulose tablets are characterized by a lower compressibility and crushing strength since cellulose crystals are softer, weaker, and less elastic [24,44].

Disintegration is the first step in the bioavailability process, used to evaluate the behavior of the product through the gastrointestinal tract [45]. The formulations with microcrystalline cellulose had lower disintegration times (1.9 and $19.3 \mathrm{~min}$ for GM and RM, respectively), while lactose tablets presented greater times ( 66 and $67 \mathrm{~min}$ for GL and RL, respectively). These differences may be related to the low compressibility of microcrystalline cellulose and its rapid swelling in a humid environment. However, if there is erosion on the tablets, it may explain why tablets of similar mass show little difference in the dissolution profiles [46]. In comparison with other studies, slower disintegration for tablets with lactose derivatives is reported [44]. Other studies on tablets made with pectin from citrus peel exhibited disintegration times of between 12 and $15 \mathrm{~min}$ [39], and the times for banana peel tablets were 8-10 min [21]. These differences can be explained by the geometry playing an important role—tablets with larger surface area have faster drug release and disintegration [46] —and the variation in particle size [45]. In this context, the GL tablet presented greater resistance to breakage, less friability, and a longer disintegration time compared to the other excipients. These differences can be explained by the influence of the different excipients analyzed and their physical and chemical properties, given that several researchers have reported that the excipients are a critical factor in the development of new pharmaceutical formulations with greater pharmacological functionality (disintegration, dissolution, release, and bioavailability of the drug) $[47,48]$.

\subsection{Scanning Electron Microscopy (SEM)}

SEM images of the cactus pear powder and formulations are shown in Figure 1. The structure of the green and red cactus pear powders (Figure 1A,D) without excipients was continuous but with irregular borders. Images of the GM and RM tablets (Figure 1B,E) also showed the structure of the added excipients. The typical structure of microcrystalline cellulose (labeled "a" in the figure) was observed as elongated filamentary structures with angular borders [49], while the lactose structures (labeled " $\mathrm{b}$ ") were rather small, spherical and without angular edges. The structure of the matrix by itself, in combination with the structure of an excipient, influences the behavior of the sample; for example, the filamentous structures of the microcrystalline cellulose give greater force against abrasion, while the spherical lactose structures provide greater cohesion between the particles, allowing longer disintegration times [50-52].

\subsection{Functional Properties: Lipid and Water Holding Capacity}

In previous studies performed by Bensadón et al. on the same raw material of cactus pear wastes used in this work, the amount of dietary fiber was reported as follows: for the green residues, $34.9 \mathrm{~g} / 100 \mathrm{~g}$ insoluble fiber and $7.9 \mathrm{~g} / 100 \mathrm{~g}$ soluble fiber; for the red residues, $19.3 \mathrm{~g} / 100 \mathrm{~g}$ insoluble fiber and $8.1 \mathrm{~g} / 100 \mathrm{~g}$ soluble fiber [53]. Thus, the fiber content of each tablet is $0.24 \mathrm{~g}$ with green residues and $0.15 \mathrm{~g}$ with red residues, approximately. According to the recommended daily intake of fiber for adults (25-30 g/day) [54], in the present study, the daily portion of consumption would be six tablets per day; therefore, the tablets would cover $5.7 \%$ (green tablets) and $2.6 \%$ (red tablets). Although the content of fiber is low, the impact in terms of the physiological benefits and in the food industry could be important. According to Cardenas et al., the fiber in the cactus pear fruit is characterized by a high insoluble dietary fiber content and the presence of mucilages with high molecular weight which interact in an entangled network, able to hydrate and increase the viscosity of the liquid phase in the food system [55]. Therefore, the physicochemical properties of these samples could be affected in the presence of water. 


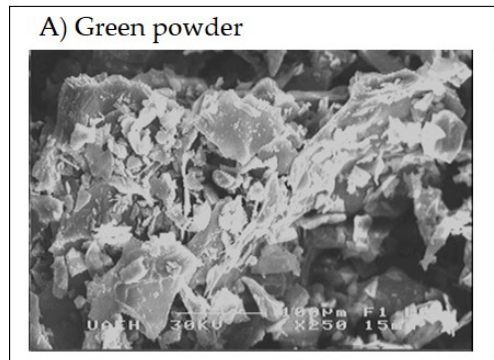

D) Red powder

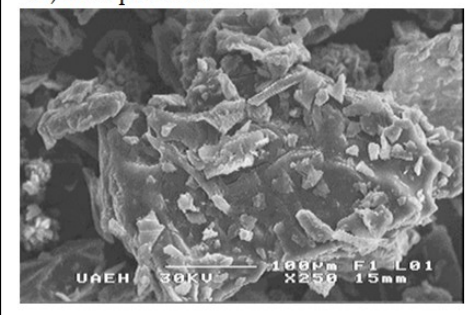

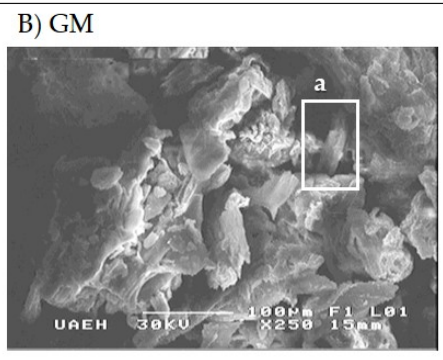

E) RM

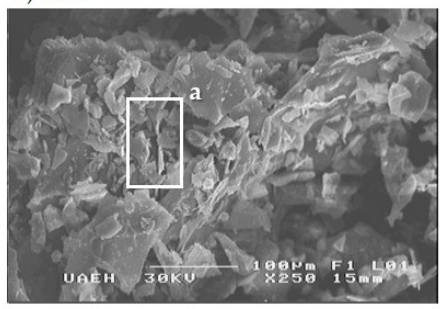

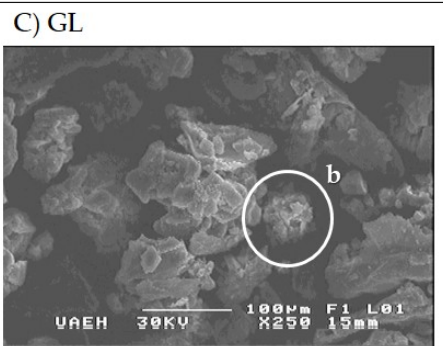

F) RL

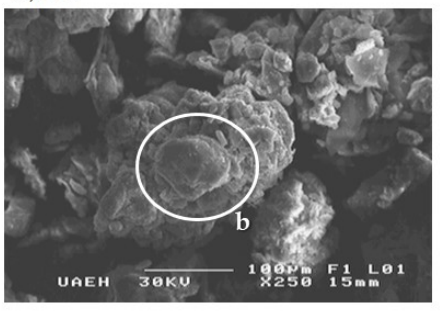

Figure 1. Scanning electron microscopy images of cactus pear (Opuntia ficus-indica) residue tablets, 250×. (A) Green cactus pear powder (without excipient); (B) GM: green cactus pear residue with microcrystalline cellulose; (C) GL: green cactus pear residue with lactose; (D) Red cactus pear residue powder (without excipient); (E) RM: red cactus pear residue with microcrystalline cellulose; (F) RL: red cactus pear residue with lactose. a: Aggregates of microcrystalline cellulose; b: Aggregates of lactose.

For the LHC and WHC parameters presented, the GM formulation had the highest values, in contrast with the RL formulation, which had the lowest values for both parameters (Table 1). The lipid and water holding capacity may be attributed to the high amount of insoluble fiber in the cactus pear residue, which is capable of trapping oil and water particles in its structure [56,57]. The structure of the microcrystalline cellulose fiber favors retention [44], and this could explain the faster disintegration of these tablets compared to the lactose formulations (Table 1). Other studies on fibers from fruit by-products have reported good water and lipid retention. For example, a fiber supplement from lemon peel presented $5 \mathrm{~g} / \mathrm{g}$ and $7 \mathrm{~g} / \mathrm{g}$ WRC and LRC, respectively, while pineapple peel presented $11 \mathrm{~g} / \mathrm{g}$ and $6 \mathrm{~g} / \mathrm{g}$ WRC and LRC, respectively [20,58]. However, these properties have not been reported in other dietary supplements in solid dosage forms, though they are physiologically important, since WHC leads to the hydration of the intestinal content for soft and easy-to-pass stools, and LHC has clinical significance in certain disorders of colonic function, obesity, and lipid blood concentrations [59].

\subsection{Color}

The four formulations presented a heterogeneous aspect and characteristic color corresponding to the cactus pear residue variety used (Figure 2). Color is an important quality attribute that influences consumer choices and preferences [31].

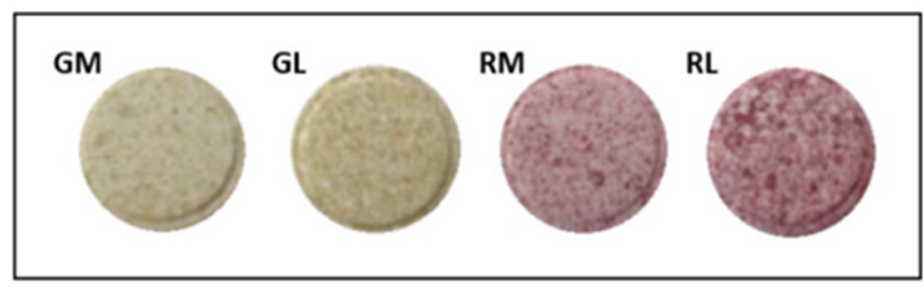

Figure 2. Images of tablet formulations of cactus pear (Opuntia ficus- indica L. Mill) residue. GM: green cactus pear residue with microcrystalline cellulose; GL: green cactus pear residue with lactose; RM: red cactus pear residue with microcrystalline cellulose; RL: red cactus pear residue with lactose. 
The color parameters are shown in Table 2. Green tablets had the highest values $(p<0.05)$ for luminosity $\left(L^{*}\right)$, having a brighter color than red tablets. For the green tablets, the $a^{*}$ values were negative and $b^{*}$ values were positive, which places them in the green-yellow quadrant, while the red tablets presented positive values for $a^{*}$ and $b^{*}$, corresponding to the red-yellow quadrant.

Table 2. Color parameters of the cactus pear residue tablet formulations.

\begin{tabular}{ccccc}
\hline & GM & GL & RM & RL \\
\hline$L^{*}$ & $49 \pm 0^{\mathrm{a}}$ & $48 \pm 1^{\mathrm{a}}$ & $40 \pm 1^{\mathrm{b}}$ & $41 \pm 0^{\mathrm{b}}$ \\
$a^{*}$ & $-2 \pm 0^{\mathrm{c}}$ & $-2 \pm 0^{\mathrm{c}}$ & $7 \pm 0^{\mathrm{b}}$ & $9 \pm 0^{\mathrm{a}}$ \\
$\mathrm{b}^{*}$ & $16 \pm 0^{\mathrm{a}}$ & $15 \pm 0^{\mathrm{a}}$ & $4 \pm 0^{\mathrm{b}}$ & $4 \pm 0^{\mathrm{b}}$ \\
$\mathrm{h}^{\circ}$ & $97 \pm 0^{\mathrm{a}}$ & $98 \pm 0^{\mathrm{a}}$ & $31 \pm 1^{\mathrm{b}}$ & $25 \pm 0^{\mathrm{c}}$ \\
$\mathrm{C}^{*}$ & $16 \pm 0^{\mathrm{a}}$ & $15 \pm 0^{\mathrm{a}}$ & $9 \pm 0^{\mathrm{c}}$ & $11 \pm 0^{\mathrm{b}}$ \\
\hline
\end{tabular}

Mean values \pm standard deviations $(n=3)$. ${ }^{\text {a-d }}$ Superscript letters indicate significant differences $(p<0.05)$ between tablet formulations. GM: green cactus pear residue with microcrystalline cellulose; GL: green cactus pear residue with lactose; RM: red cactus pear residue with microcrystalline cellulose; RL: red cactus pear residue with lactose. $L^{*}$ values of 0 and 100 indicate black and white, respectively, $a^{*}$ is the axis of chromaticity between green $(-)$ and red $(+), b^{*}$ is the axis between blue $(-)$ and yellow $(+), h^{\circ}$ indicate Hue angle and $C^{*}$ indicate chroma parameters.

The inclusion of binding agents within the same variety of cactus pear had no significant effect on $a^{*}$ and $b^{*}$ values, so the characteristic color of the fruits was preserved by the peel color itself. Both GM and GL tablets exhibited negative hue $\left(h^{\circ}\right)$ values; according to McLellan, the addition of $180^{\circ}$ to a negative value allows us to achieve a positive one [60], and with this adjustment it was possible to determine the yellowish tonalities for the GM tablets and reddish or pink ones for the RM and RL samples. The chroma $\left(C^{*}\right)$ value estimates the quantitative attribute of colorfulness, with higher chroma values indicating higher color intensity of samples as perceived by humans [31]. The green cactus pear formulations (GM and GL) presented higher $\mathrm{C}^{*}$ values, followed by RL and RM, so red formulations had less intense tonalities. All samples preserved the color characteristic of the variety used, and attractive colors were observed (Figure 2); therefore, it is not necessary to add artificial colors to make them attractive to the consumer. Besides, cactus pear pigments have been widely used by the food industry as an economical and stable source of pigments [61].

\subsection{Antioxidant Properties}

The antioxidant properties of the formulations are shown in Table 3. Despite reports that red cactus pear has higher total phenolic content (TPC) in the pulp than in the peel and seeds [62], the results in terms of phenolic compounds were higher $(p<0.05)$ in GL, followed by GM. The TPC in the red cactus pear formulations (RM and RL) did not differ significantly; however, Cejudo et al. reported that yellow varieties of whole cactus pear fruit have higher contents of phenolic compounds in the pericarp and epicarp than in the pulp [63]. Regarding antioxidant activity by DPPH, the radical inhibition of the red formulations was higher $(24 \%)$ when compared to the green tablets $(20 \%)$. Differences in antioxidant activity between green and red cactus pear residues were also found by Ramirez-Moreno et al., where seeds from green cactus pear showed greater antioxidant activity than the red variety [64]. These differences in antioxidant capacity could be linked to the antioxidants of lipophilic nature associated with different cactus pear varieties, for instance, lipophilic compounds such as tocopherols may increase the antioxidant activity measured by DPPH [33]. The antioxidant activity by ABTS was similar $(p>0.05)$ among all the tablets. Finally, the RM formulation exhibited higher FRAP values $(p<0.05)$. Although studies on the antioxidant properties of tablets with added fruit wastes are limited, a study on effervescent tablets made with tangerine peel reported a $141 \mathrm{mg} \mathrm{GAE} / 100 \mathrm{~g}$ total phenolic content and 27\% DPPH inhibition percentage [65], which are lower and slightly higher, respectively, than the cactus pear residue tablets These results are interesting and are in accord with the study by Bensandon et al.; cactus pear by-products have the potential to be used in the development of food products because their high dietary fiber and antioxidant content can prevent the damage caused by 
free radicals [53]. The measures of antioxidant status help to determine why a diet high in antioxidants is often more beneficial, since dietary antioxidants have the ability to inhibit the formation of both reactive oxygen species (ROS) and reactive nitrogen species (RNS), which can adversely affect normal cellular processes and physiological functions. It is well known that excessive oxidative stress could affect proteins, lipids, or genetic material, leading to decreased immune competence and increased inflammatory response, all linked to several diseases such as cancer, cardiovascular disease, obesity and diabetes [66].

Table 3. The antioxidant properties of the cactus pear residue tablet formulations.

\begin{tabular}{ccccc}
\hline & GM & GL & RM & RL \\
\hline TPC (mg GAE/100 g) & $718 \pm 11^{\mathrm{b}}$ & $734 \pm 8^{\mathrm{a}}$ & $649 \pm 12^{\mathrm{c}}$ & $651 \pm 8^{\mathrm{c}}$ \\
DPPH (\% Inhibition) & $20 \pm 1^{\mathrm{b}}$ & $20 \pm 2^{\mathrm{b}}$ & $24 \pm 2^{\mathrm{a}}$ & $24 \pm 1^{\mathrm{a}}$ \\
ABTS ( $\mu \mathrm{mol} \mathrm{TE} / 100 \mathrm{~g})$ & $4628 \pm 412^{\mathrm{a}}$ & $4637 \pm 242^{\mathrm{a}}$ & $4365 \pm 392^{\mathrm{a}}$ & $4610 \pm 326^{\mathrm{a}}$ \\
FRAP $(\mu \mathrm{mol} \mathrm{Fe} / 100 \mathrm{~g})$ & $17 \pm 0^{\mathrm{b}}$ & $16 \pm 1^{\mathrm{c}}$ & $19 \pm 0^{\mathrm{a}}$ & $17 \pm 0^{\mathrm{b}}$ \\
\hline
\end{tabular}

Mean values \pm standard deviation $(n=3)$. ${ }^{\text {a-c }}$ Superscript letters indicate significant differences $(p<0.05)$ between tablet formulations. GM: green cactus pear residue with microcrystalline cellulose; GL: green cactus pear residue with lactose; RM: red cactus pear residue with microcrystalline cellulose; RL: red cactus pear residue with lactose. Gallic acid (for total phenolic content (TPC)), Trolox (for DPPH and ABTS), and $\mathrm{FeSO}_{4}$ (for ferric reducing/antioxidant power (FRAP)) were used as reference standards.

On the other hand, studies have been carried out regarding the safety of the consumption of cactus pear fruit; for example, the presence of pesticide residues (malathion, chlorpyrifos, permethrin, diazinon, dimethoate, spinosad, and abamectin) and heavy metals (copper, chromium, arsenic, cadmium, lead, and selenium) has been demonstrated in levels less than the maximum limits of toxic residues established by the North American Free Trade Agreement [67,68], indicating that these phytotoxic elements do not trigger toxicological health risks.

\section{Conclusions}

Based on the results obtained, cactus pear residue is proposed as an interesting nutritional supplement for the market due to its good quality parameters, fiber functional properties, acceptable color for consumers, and high antioxidant activity, providing probable benefits to consumers. The GL formulation presented better performance as a possible dietary supplement.

Further research on phytotoxicity is needed since there are no existing reports about that, as well as, in vivo model studies in order to evaluate the health effects of a dietary supplement developed from cactus pear by-products.

Author Contributions: Conceptualization, N.d.S.C.-C.; Methodology, S.M.-V.; Formal Analysis, O.A.J.-M.; Data Curation, E.R.-M. and J.A.-R.; Writing-Original Draft Preparation, S.M.-V.; E.R.-M.; J.A.-R., O.A.J.-M., Z.G.C.-R.; L.D.-O.; M.C.-D., D.C.-D. and N.d.S.C.-C.; Writing-Review and Editing, S.M.-V.; E.R.-M.; J.A.-R., O.A.J.-M., Z.G.C.-R.; L.D.-O.; M.C.-D., D.C.-D. and N.d.S.C.-C.; Supervision, N.d.S.C.-C. All authors have read and agreed to the published version of the manuscript.

Funding: The first author would like to thank the Consejo Nacional de Ciencia y Tecnología (CONACyT) for the fellowship assigned (CVU 708817).

Acknowledgments: We thank the Mexican Association CoMeNTuna (Actopan, Hidalgo, México) for providing the plant material.

Conflicts of Interest: The authors declare no conflict of interest.

Strengths and Limitations: The strengths of the present study consist of the use of an agricultural by-product, through its use in a novel product, which may have beneficial effects on human health and which also represents an economic benefit for the producers of the fruit. On the other hand, among the limitations, the cactus pear is a seasonal fruit, so the residues must be collected and stored during the harvest season. It is also necessary to subject the product to further in vitro tests in order to evaluate any positive or negative effects on human health. 


\section{References}

1. Block, G.; Jensen, C.; Norkus, E.; Dalvi, T.; Wong, L.; McManus, J. Usage patterns, health, and nutritional status of long-term multiple dietary supplement users: A cross-sectional study. Nutr. J. 2008, 6, 30. [CrossRef] [PubMed]

2. Radimer, K.; Bindewald, B.; Hughes, J.; Ervin, B.; Swanson, C.; Picciano, M.F. Dietary supplement use by US adults: Data from the national health and nutrition examination survey, 1999-2000. Am. J. Epidemiol. 2004, 160, 339-349. [CrossRef] [PubMed]

3. U.S. Food \& Drug Administration. Dietary Supplements, 2019. U.S. Food \& Drug Administration Website. Available online: https://www.fda.gov/consumers/consumer-updates/dietary-supplements (accessed on 21 April 2020).

4. Da Costa, A.G.; Nunes, M.A.; Almeida, I.; Carvalho, M.; Barroso, M.F.; Alves, R.C.; Oliveira, M.B.P.P. Teas, dietary supplements and fruit juices: A comparative study regarding antioxidant activity and bioactive compounds. LWT 2012, 49, 324-328. [CrossRef]

5. Di Mauro, M.D.; Tomasello, B.; Giardina, R.C.; Dattilo, S.; Mazzei, V.; Sinatra, F.; Caruso, M.; D’Antona, N.; Renis, M. Sugar and mineral enriched fraction from olive mill wastewater for promising cosmeceutical application: Characterization, in vitroandin vivostudies. Food Funct. 2017, 8, 4713-4722. [CrossRef]

6. Varzakas, T.; Zakynthinos, G.; Verpoort, F. Plant food residues as a source of nutraceuticals and functional foods. Foods 2016, 5, 88. [CrossRef]

7. Gurrieri, S.; Miceli, L.; Lanza, C.M.; Tomaselli, F.; Bonomo, R.P.; Rizzarelli, E. Chemical characterization of sicilian prickly pear (Opuntia ficus indica) and perspectives for the storage of its juice. J. Agric. Food Chem. 2000, 48, 5424-5431. [CrossRef]

8. Jiménez-Aguilar, D.M.; Avellaneda, Z.J.E.; Martín-Belloso, O.; Gutiérrez-Uribe, J.; Valdez-Fragoso, A.; García-García, R.; Torres, J.A.; Welti-Chanes, J. Effect of high hydrostatic pressure on the content of phytochemical compounds and antioxidant activity of prickly pears (opuntia ficus-indica) beverages. Food Eng. Rev. 2015, 7, 198-208. [CrossRef]

9. Moßhammer, M.R.; Stintzing, F.C. Cactus pear fruits (Opuntia spp.): A review of processing technologies and current uses. J. Prof. Assoc. Cactus. 2006, 8, 1-25.

10. Ramírez-Moreno, E.; Hervert-Hernández, D.; Sánchez-Mata, M.C.; Díez-Marqués, C.; Goñi, I. Intestinal bioaccessibility of polyphenols and antioxidant capacity of pulp and seeds of cactus pear. Int. J. Food Sci. Nutr. 2011, 62, 839-843. [CrossRef]

11. Galati, E.; Tripodo, M.; Trovato, A.; Miceli, N.; Monforte, M. Biological effect of Opuntia ficus indica (L.) Mill. (Cactaceae) waste matter. J. Ethnopharmacol. 2002, 79, 17-21. [CrossRef]

12. Barba, F.J.; Putnik, P.; Kovačević, D.B.; Poojary, M.M.; Roohinejad, S.; Lorenzo, J.M. Impact of conventional and nonconventional processing on prickly pear (Opuntia spp.) and their derived products: From preservation of beverages to valorization of by-products. Trends Food Sci Technol. 2017, 67, 260-270. [CrossRef]

13. El-Mostafa, K.; El-Kharrassi, Y.; Badreddine, A.; Andreoletti, P.; Vamecq, J.; El-Kebbaj, M.; Latruffe, N.; Lizard, G.; Nasser, B.; Cherkaoui-Malki, M.; et al. Nopal cactus (opuntia ficus-indica) as a source of bioactive compounds for nutrition, health and disease. Molecules 2014, 19, 14879-14901. [CrossRef] [PubMed]

14. Jiménez-Aguilar, D.M.; López-Martínez, J.M.; Hernández-Brenes, C.; Gutiérrez-Uribe, J.A.; Welti-Chanes, J. Dietary fiber, phytochemical composition and antioxidant activity of Mexican commercial varieties of cactus pear. J. Food Compost. Anal. 2015, 41, 66-73. [CrossRef]

15. El-Kossori, R.L.; Villaume, C.; El-Boustani, E.; Sauvaire, Y.; Mejean, L. Composition of pulp, skin and seeds of prickly pears fruit (Opuntia ficus-indica sp.). Plant Food Hum. Nutr. 1998, 52, 263-270. [CrossRef]

16. Saura-Calixto, F.; Serrano, J.; Goñi, I. Intake and bioaccessibility of total polyphenols in a whole diet. Food Chem. 2007, 101, 492-501. [CrossRef]

17. Hernández-Carranza, P.; Jattar-Santiago, K.Y.; Avila-Sosa, R.; Pérez-Xochipa, I.; Guerrero-Beltrán, J.A.; Ochoa-Velasco, C.E.; Ruiz-López, I. Antioxidant fortification of yogurt with red cactus pear peel and its mucilage. CyTA-J. Food 2019, 17, 824-833. [CrossRef]

18. Namir, M.; Elzahar, K.; Ramadan, M.F.; and Allaf, K. Cactus pear peel snacks prepared by instant pressure drop texturing: Effect of process variables on bioactive compounds and functional properties. J. Food Meas. Charact. 2017, 11, 388-400. [CrossRef] 
19. Chougui, N.; Djerroud, N.; Naraoui, F.; Hadjal, S.; Aliane, K.; Zeroual, B.; Larbat, R. Physicochemical properties and storage stability of margarine containing Opuntia ficus-indica peel extract as antioxidant. Food Chem. 2015, 173, 382-390. [CrossRef]

20. Huang, Y.L.; Chow, C.J.; Fang, Y.J. Preparation and physicochemical properties of fiber-rich fraction from pineapple peels as a potential ingredient. J. Food Drug Anal. 2011, 19, 318-323.

21. Bansal, J.; Malviya, R.; Malaviya, T.; Bhardwaj, V.; Sharma, P. Evaluation of Banana peel Pectin as excipient in solid Oral Dosage Form. Glob. J. Pharm. 2014, 8, 275-278.

22. Srivastava, P.; Malviya, R. Extraction, characterization and evaluation of orange peel waste derived pectin as a pharmaceutical excipient. Nat. Prod. J. 2011, 1, 65-70. [CrossRef]

23. Urakov, A.; Urakova, N.; Reshetnikov, A.; Kasatkin, A.; Kopylov, M.; Baimurzin, D. About what is happening in the stomach after swallowing human river pebbles, gravel, chalk, clay and tablets drugs. Építöanyag (Online). Epitoanyag-J. Silic. Based Compos. Mater. 2016, 4, 110. [CrossRef]

24. Osei-Yeboah, F.; Sun, C.C. Validation and applications of an expedited tablet friability method. Int. J. Pharm. 2009, 484, 146-155. [CrossRef] [PubMed]

25. Dirección General de Normas. Non industrialized food products for human use, fresh fruit Cactus pear (Opuntia spp.) Specifications. Available online: https://www.colpos.mx/bancodenormas/nmexicanas/NMXFF-030-1995.PDF (accessed on 13 March 2020).

26. Uniformity of Dosage Units (USP 911), 2011. Pharmacopeia US. Available online: https://www.usp.org/ sites/default/files/usp/document/harmonization/gen-method/q0304_stage_6_monograph_25_feb_2011.pdf (accessed on 13 January 2019).

27. Tablet Breaking Force (USP 1217), 2016. Pharmacopeia US. Available online: https://www.in-pharmatechnologist. com/Library/USP-1217-Tablet-Breaking-Force-A-New-Chapter-for-Tablet-Hardness-Testing (accessed on 13 January 2019).

28. Tablet Friability (USP 1216), 2016. Pharmacopeia US. Available online: https://www.usp.org/sites/default/ files/usp/document/harmonization/gen-chapter/g06_pf_ira_32_2_2006.pdf (accessed on 13 January 2019).

29. Disintegration (USP 701), 2019. Pharmacopeia US. Available online: https://www.usp.org/sites/default/files/ usp/document/harmonization/gen-chapter/april-2019-m99460.pdf (accessed on 13 January 2019).

30. Valencia, F.; Román, M. Physicalchemical and functional characterization of three commercial concentrates from dietary fiber. Vitae 2006, 13, 54-60.

31. Pathare, P.B.; Umezuruike, L.O.; Al-Said, F.A.J. Colour measurement and analysis in fresh and processed foods: A review. Food Bioprocess Technol. 2013, 6, 36-60. [CrossRef]

32. Stintzing, F.C.; Herbach, K.M.; Mosshammer, M.R.; Carle, R.; Yi, W.; Sellappan, S.; Akoh, C.C.; Bunch, R.; Felker, P. Color, betalain pattern, and antioxidant properties of cactus pear (Opuntia spp.) clones. J. Agric. Food Chem. 2005, 53, 442-451. [CrossRef]

33. Kuskoski, E.M.; Asuero, A.G.; Troncoso, A.M.; Mancini-Filho, J.; Fett, R. Aplicación de diversos métodos químicos para determinar actividad antioxidante en pulpa de frutos. Food Sci. Technol. 2005, 25, 726-732. [CrossRef]

34. Aguirre, J.J.; De-La-Garza, T.H.; Zugasti, A.; Ruth, C.; Noé, A.C.; Heliodoro, D.L.G.T.; Jasso, R.M.R. The optimization of phenolic compounds extraction from cactus pear (Opuntia ficus-indica) skin in a reflux system using response surface methodology. Asian Pac. J. Trop. Biomed. 2013, 6, 436-442. [CrossRef]

35. Zafra-Rojas, Q.; Cruz-Cansino, N.; Delgadillo-Ramírez, A.; Alanís-García, E.; Añorve-Morga, J.; Quintero-Lira, A. Organic acids, antioxidants, and dietary fiber of mexican blackberry (rubus fruticosus) residues cv. Tupy. J. Food Qual. 2018, 6, 436-442. [CrossRef]

36. Wu, C.; Seville, J.P. A comparative study of compaction properties of binary and bilayer tablets. Powder Technol. 2009, 189, 285-294. [CrossRef]

37. Awofisayo, S.O.; Awofisayo, O.A.; Eyen, N.; Udoh, I.E. Comparative assessment of the quality control measurements of multisource ofloxacin tablets marketed in Nigeria. Dissolution Technol. 2010, 17, $20-25$. [CrossRef]

38. Patel, S.; Kaushal, A.M.; Bansal, A.K. Compression physics in the formulation development of tablets. Crit. Rev. Ther. Drug Carr. Syst. 2006, 23, 1-65. [CrossRef] [PubMed]

39. Khule, N.R.; Mahale, N.B.; Shelar, D.S.; Rokade, M.M.; Chaudhari, S.R. Extraction of pectin from citrus fruit peel and use as natural binder in paracetamol tablet. Der. Pharm. Lett. 2012, 4, 558-564. 
40. US Department of Health and Human Services \& F. and DA. Size, Shape, and Other Physical Attributes of Generic Tablets and Capsules Guidance for Industry, 2015. U.S. Food \& Drug Administration Website. Available online: http://www.fda.gov/Drugs/GuidanceComplianceRegulatoryInformation/Guidances/default. html (accessed on 13 March 2020).

41. Divate, S.; Kavitha, K.; Sockan, G.N. Fast disintegrating tablets-An emerging trend. Int. J. Pharm. Sci. Rev. Res. 2011, 6, 2.

42. Patel, S.; Sun, C.C. Macroindentation hardness measurement modernization and applications. Int. J. Pharm. 2016, 506, 262-267. [CrossRef] [PubMed]

43. Porter, S.; Sackett, G.; Liu, L. Development, optimization, and scale-up of process parameters: Pan coating. In Developing Solid Oral Dosage Forms; Academic Press: Cambridge, MA, USA, 2017; pp. 953-996.

44. Gohel, M.C.; Jogani, P.D. A review of co-processed directly compressible excipients. J. Pharm. Pharm. Sci. 2005, 8, 76-93.

45. Quodbach, J.; Kleinebudde, P. Performance of tablet disintegrants: Impact of storage conditions and relative tablet density. Pharm. Dev. Technol. 2015, 6, 762-768. [CrossRef]

46. Goyanes, A.; Martinez, P.R.; Buanz, A.; Basit, A.W.; Gaisford, S. Effect of geometry on drug release from 3D printed tablets. Int. J. Pharm. 2015, 494, 657-663. [CrossRef]

47. Pishnamazi, M.; Iqbal, J.; Shirazian, S.; Walker, G.M.; Collins, M.N. Effect of lignin on the release rate of acetylsalicylic acid tablets. Int. J. Biol. Macromol. 2019, 124, 354-359. [CrossRef]

48. Van Den Mooter, G. The use of amorphous solid dispersions: A formulation strategy to overcome poor solubility and dissolution rate. Drug Discov. Today: Technol. 2012, 9, 79-85. [CrossRef]

49. Filson, P.B. Sono-chemical preparation of cellulose nanocrystals from lignocellulose derived materials. Bioresour. Technol. 2009, 7, 2259-2264. [CrossRef] [PubMed]

50. Boschini, F.; Delaval, V.; Traina, K.; Vandewalle, N. Linking flowability and granulometry of lactose powders. Int. J. Pharm. 2015, 494, 312-320. [CrossRef] [PubMed]

51. Villafuerte-Robles, L. The excipients and their functionality in pharmaceutical solid products. Rev. Mex. Cienc. Farm. 2011, 42, 18-36. [CrossRef]

52. Kaerger, J.S.; Edge, S.; Price, R. Influence of particle size and shape on flowability and compactibility of binary mixtures of paracetamol and microcrystalline cellulose. Eur. J. Pharm. Sci. 2004, 22, 173-179. [CrossRef] [PubMed]

53. Bensadón, S.; Hervert-Hernández, D.; Sáyago-Ayerdi, S.G.; Goñi, I. By-products of Opuntia ficus-indica as a source of antioxidant dietary fiber. Plant Foods Hum. Nutr. 2010, 65, 210-216. [CrossRef] [PubMed]

54. Cho, S.S. Handbook of Dietary Fiber; CRC Press: Boca Raton, FL, USA, 2001.

55. Cardenas, A.; Higuera-Ciapara, I.; Goycoolea, F. Rheology and aggregation of cactus (Opuntia ficus indica) mucilage in solution. J. Prof. Assoc. Cactus Dev. 1997, 2, 152-159.

56. Cardador-Martínez, A.; Jiménez-Martínez, C.; Sandoval, G. Revalorization of cactus pear (Opuntia spp.) wastes as a source of antioxidants. Food Sci. Technol. 2011, 31, 782-788. [CrossRef]

57. Chamorro, R.A.M.; Mamani, E.C. Importancia de la fibra dietética, sus propiedades funcionales en la alimentación humana y en la industria alimentaria. Rev. Investing Cienc. Tecnol. Aliment. 2010, 1, 4-17.

58. Lario, Y.E.; Sendra, E.; Garcia-Pérez, J.; Fuentes, C.; Sayas-Barberá, E.; Fernández-López, J. Preparation of high dietary fiber powder from lemon juice by-products. Innov. Food Sci. Emerg. 2004, 5, 113-117. [CrossRef]

59. Caprita, A.; Caprita, R.; Simulescu, V.O.; Drehe, R.M. Dietary fiber: Chemical and functional properties. J. Agroaliment Process Technol. 2010, 16, 406-410.

60. McLellan, M.R.; Lind, L.R. Hue angle determinations and statistical analysis for multiquadrant Hunter, L., a, b data. J. Food Qual. 1995, 3, 235-240. [CrossRef]

61. Sánchez, F.D.; López, E.M.S.; Kerstupp, S.F.; Ibarra, R.V.; Scheinvar, L. Colorant extraction from red prickly pear (Opuntia lasiacantha) for food application. Electron. J. Environ. Agric. Food Chem. 2006, 5, 1330-1337.

62. Cota-Sánchez, J.H. Nutritional composition of the prickly pear (Opuntia ficus-indica) fruit. In Nutritional Composition of Fruit Cultivars; Academic Press: Cambridge, MA, USA, 2016; pp. 691-712.

63. Cejudo-Bastante, M.J.; Chaalal, M.; Louaileche, H.; Parrado, H.J.; Heredia, F.J. Betalain profile, phenolic content, and color characterization of different parts and varieties of Opuntia ficus-indica. J. Agric. Food Chem. 2014, 62, 8491-8499. [CrossRef] [PubMed]

64. Ramírez-Moreno, E.; Cariño-Cortés, R.; Cruz-Cansino, N.D.S.; Delgado-Olivares, L.; Ariza-Ortega, J.A.; Montañez-Izquierdo, V.Y.; Hernández-Herrero, M.M.; Filardo-Kerstupp, T. Antioxidant and Antimicrobial Properties of Cactus Pear (Opuntia) Seed Oils. J. Food Qual. 2017, 2017, 1-8. [CrossRef] 
65. Tokuşoğlu, Ö. Innovative mandarin peel effervescent tablet as antioxidant and anticarcinogen food supplement: Bioactive flavanones and phenolic acids by HPLC-DAD and LC-esiqtoff mass spectrometry. Food Health Technol. Innov. 2018, 1, 75-80.

66. Seifried, R.M.; Harrison, E.; Seifried, H.E. Antioxidants in health and disease. Nutr. Prev. Treat. Dis. 2017, $321,346$.

67. Aguilera, C.A.; Tovar, J.C.; Rosales, S.A.; Pérez, L.; Guadalupaseso, M.; Arroyo, H.S.; Hernández, M.S. Límites máximos de residuos e intervalos de seguridad de plaguicidas en tuna, Opuntia ficus-indica. Master's Thesis, Colegio de Postgraduados (COLPOS) Consejo Nacional de Ciencia y Tecnología (CONACYT), Mexico City, Mexico, 2008.

68. Mottese, A.F.; Naccari, C.; Vadalà, R.; Bua, G.D.; Bartolomeo, G.; Rando, R.; Giacomo, D.; Nicola, C. Traceability of Opuntia ficus-indica L. Miller by ICP-MS multi-element profile and chemometric approach. J. Sci. Food Agric. 2018, 98, 198-204. [CrossRef]

(C) 2020 by the authors. Licensee MDPI, Basel, Switzerland. This article is an open access article distributed under the terms and conditions of the Creative Commons Attribution (CC BY) license (http://creativecommons.org/licenses/by/4.0/). 